\title{
The CPA Presidential Task Force on Evidence-Based Practice
}

\section{of Psychological Treatments ${ }^{1}$}

\author{
David J. A. Dozois, University of Western Ontario \\ Sam Mikail, The Southdown Institute \\ Lynn E. Alden, University of British Columbia \\ Peter J. Bieling, St. Joseph's Healthcare, Hamilton \\ Guy Bourgon, Public Safety Canada, Ottawa \\ David A. Clark, University of New Brunswick \\ Martin Drapeau, McGill University \\ Dave Gallson, Mood Disorders Society of Canada \\ Les Greenberg, York University \\ John Hunsley, University of Ottawa \\ Charlotte Johnston, University of British Columbia
}

\section{AUTHOR'S PREPUBLICATION COPY}

\section{Corresponding Author}

David J. A. Dozois, Ph.D., C.Psych.

Department of Psychology

The University of Western Ontario

Westminster Hall, Rm. 313E

London, Ontario, CANADA

N6A 3K7

tel: (519) 661-2111 ext. 84678

email: ddozois@uwo.ca

${ }^{1}$ This article describes the report of the CPA Task Force on Evidence-Based Practice of Psychological Treatments (Evidence-Based Practice of Psychological Treatments: A Canadian Perspective, (C) 2012) available at http://www.cpa.ca/aboutcpa/committees/cpataskforces. Portions of this report are reprinted in this article with permission from the Canadian Psychological Association. 


\begin{abstract}
The Board of Directors of the Canadian Psychological Association (CPA) launched a Task Force on Evidence-Based Practice of Psychological Treatments to support and guide practice as well as to inform stakeholders. This article describes the work of this Task Force, outlining its raison d'etre, providing a comprehensive definition of evidence-based practice (EBP), and advancing a hierarchy of evidence that is respectful of diverse research methodologies, palatable to different groups, and yet comprehensive and compelling. The primary objective was to present an overarching methodology or approach to thinking about EBP so that psychologists can provide and implement the best possible psychological treatments. To this end, our intention for this document was to provide a set of guidelines and standards that will foster interest, encourage development, and promote effectiveness in EBP.
\end{abstract}

Keywords: evidence-based practice; evidence-based treatment; empirically supported treatment; decision-making; psychotherapy; psychological treatment 
Evidence-Based Practice 3

\section{The CPA Presidential Task Force on Evidence-Based Practice of Psychological Treatments}

As part of the 2011-2012 CPA President's mandate (see Dozois, 2012, 2013), the Board of Directors voted in favour of a motion (March, 2011) that the CPA establish a Task Force on the evidence-based practice of psychological treatments which would generate a set of criteria and develop a position statement regarding the optimal integration of research evidence into practice. The Board members believed that it was important for CPA to develop a position on evidence-based practice in psychology to support and guide practice as well as to inform stakeholders. Psychological health and psychological disorders are clearly a priority for many of Canada's stakeholder groups (e.g., Mental Health Commission of Canada, Treasury Board, Public Health Agency of Canada) and effective psychological treatment is an important priority for CPA as well.

\section{Background}

Important objectives in professional psychology include the generation of treatmentrelevant scientific knowledge and the application of this knowledge to the development of efficacious and effective interventions for mental and behavioural health problems (Baker, McFall, \& Shoham, 2008; Kazdin, 2008; Lilienfeld, 2010; Treat, Bootzin, \& Baker, 2012). Such objectives arise from a growing recognition in the field that the practice of psychological treatments should be based on valid evidence regarding which approaches to intervention are most likely to be successful. Although there is controversy regarding what constitutes "evidence," the vast majority of psychologists believe that they should practice in a manner that is evidence-based. 
In 1995, the American Psychological Association's (APA) Society of Clinical Psychology Task Force on Promotion and Dissemination of Psychological Procedures published its initial report, which listed treatments considered to be either well-established or probably efficacious according to a standard set of criteria (e.g., Chambless \& Ollendick, 2001; Chambless et al., 1996). These criteria were subsequently adopted by the CPA Section on Clinical Psychology in their Task Force report, Empirically Supported Treatments in Psychology: Implications for Canadian Professional Psychology (Hunsley, Dobson, Johnston, \& Mikail, 1999a, 1999b).

Although many researchers and practitioners were enthusiastic about these efforts to promote empirically supported treatments, the criteria used to designate such treatments elicited considerable controversy. Concerns with the focus on empirically supported treatments have done little to narrow the gap between research and practice and to alter many clinicians' utilization of scientific literature (see Hunsley, 2007a; Kazdin, 2008; Lilienfeld, Ritschel, Lunn, Cautin, \& Latzman, in press, for reviews of some of the challenges and solutions). For example, some psychologists have argued that the type of research deemed necessary to produce supportive evidence for a treatment is incompatible with schools of psychotherapy outside of the cognitive behavioural therapy (CBT) framework (e.g., Bryceland \& Stam, 2005; see Stuart \& Lilienfeld, 2007). Although randomized clinical trials (RCTs) are considered the "gold standard" for psychotherapy outcome research, there are widespread concerns that the generalizability of their findings to actual clinical practice is limited. There is, however, growing evidence that these concerns are exaggerated or overstated (Hunsley, 2007a; Hunsley \& Lee, 2007; Lee, Horvath, \& Hunsley, 2013; Teachman et al., 2012). Others have criticized the preponderance of CBT treatments that, for lack of a better term, "made the list" of empirically supported 
treatments (e.g., Westen \& Morrison, 2001). Still others contended that manualized treatments fail to address the complexities of clinical practice (see Duncan \& Reese, 2012, for review).

More recently, the APA established a task-force on evidence-based practice in psychology that attempted to acknowledge multiple types of research evidence in evaluating treatment effects. The report of this Task Force was adopted as APA policy, with the explicit statement that, "Evidence-based practice in psychology is the integration of the best available research with clinical expertise in the context of patient characteristics, culture, and preferences" (APA, 2006, p. 273; also see Spring, 2008). This policy moves beyond a simple listing of treatments with empirical support to consider other important variables that have been shown to influence clinical outcomes. Unfortunately, the APA Task Force did not operationalize what constitutes "evidence" in this policy. Rather, it "identified a continuum of data sources available to clinicians, from uncorroborated clinical observations through meta-analyses of the results of RCTs" (Stuart \& Lilienfeld, 2007, p. 615; also see Gaudiano \& Miller, in press). The Task Force report also said little about the need for ongoing idiographic evaluation of clinical services in order to guide treatment decisions after the initiation of services.

Although there are various definitions of "evidence" and understandable reactance to certain types of research designs being elevated above others, rigorous controlled research is necessary to evaluate the impact of our interventions (Dozois, 2013; Kazdin, 2008; Lilienfeld, 2010). As such, current debate in the literature focuses not so much on whether it is necessary to utilize research findings but on how research findings should be incorporated into clinical interventions.

It is also important to point out that evidence-based practice is a process by which the best evidence available is used to make optimal clinical decisions (see Hunsley, 2007a). 
Although some psychologists mistakenly equate evidence-based practice with empiricallysupported therapies, the two are not synonymous. There are, in fact, many ways to provide evidence-based treatment (e.g., by focusing on effectiveness trials and naturalistic studies or by emphasizing evidence-based procedures and principles of practice). Clinical practice should be evidence-informed but it does not need to be narrowly evidence-driven (Bohart, 2005). Similarly, research should be informed by practice to ensure that the discipline and profession are providing evidence for treatments that respond to the kinds of problems that clients bring to psychology practitioners.

\section{The Work of the CPATask Force}

The CPA Task Force on Evidence-Based Practice of Psychological Treatments was cochaired by Drs. David J. A. Dozois and Sam Mikail. The Task Force was populated during the summer and began its work in September, 2011. Task force members (11 in total) were chosen to represent a variety of research, practice, knowledge-translation, consumer, and community perspectives. There was also good representation from different theoretical orientations, including behavioural, cognitive-behavioural, emotion-focused, interpersonal, and psychodynamic perspectives. The Task Force members met a total of 12 times from September, 2011 to November, 2012 (11 teleconferences and 1 face-to-face meeting). Considerable work was also conducted via email correspondence, the use of Dropbox ${ }^{\mathrm{TM}}$ (to download documents and articles pertaining to EBP), and in various subcommittees.

The Task Force produced an initial draft document that operationalized what constitutes evidence-based practice of psychological treatment (both a definition of evidence and a hierarchy of available evidence). In terms of defining what is meant by "evidence," the members of the Task Force were interested in a definition that was comprehensive enough to incorporate the 
following ideas: (1) research evidence is central; (2) psychologists should be evidence-based not only in their general fund of knowledge but also in session-by-session work; and (3) the process of evidence-based treatments is one of collaboration with a client/patient (rather than a top down process). The next step involved establishing a hierarchy of evidence that was sound, unbiased (e.g., respectful of diverse research methodologies), and based on the best available knowledge.

At this point, the Task Force was interested in obtaining feedback on these core elements prior to completing its next steps. The consultation process involved an online survey and was completed on April 15, 2012. Input on the initial document was sought from CPA members who practice or had an interest in psychological treatments. Various organizations (e.g., Association of Canadian Psychology Regulatory Organization [ACPRO], Canadian Council of Professional Psychology Programs [CCPPP], Canadian Register of Health Service Psychologists [CRHSP]) were also contacted for their feedback. The Chairs of the following CPA Sections were also asked to respond to the consultation document: Aboriginal, Addictions, Clinical, Clinical Neuropsychology, Counselling, Criminal Justice, Family, Health, Psychoanalytic, Psychologists in Education, Rural and Northern, Sport and Exercise, and Traumatic Stress. In general, the Task Force's statements were very well received by respondents: most respondents were enthusiastic and positive about the definition and levels of evidence. The feedback was considered carefully by the Task Force members during subsequent teleconferences and a revised version of the evidence statement and hierarchy was then generated.

A series of brief vignettes that illustrated the process of EBP were then solicited from members of the Task Force and Chairs of relevant CPA Sections. Individual experts were also invited to contribute an extended vignette that outlined the process of being evidence-based in one's practice within a particular therapeutic approach. Task force members also developed a 
brochure oriented toward the public, highlighting the importance of evidence-based practice and the value of psychological interventions. A list of resources to help professional psychologists locate reliable and up to date information regarding EBP was also compiled. Finally, a set of recommendations was created to further advance the EBP of psychological treatments.

The full Task Force report is available on the CPA website (see www.cpa.ca/aboutcpa/committees/cpataskforces). Below we briefly describe each of the aforementioned components. Although an important contribution in and of itself, the Task Force report is also intended to serve as a springboard for further development and dissemination. We hope that this will be a "living" document that will continue to be used, updated, resourced, and promoted by the CPA Board and Head Office staff, CPA sections, practitioners, and scientists.

\section{Evidence-Based Practice of Psychological Treatments: A Definition}

Evidence-based practice of psychological treatments involves the conscientious, explicit, and judicious use of the best available research evidence to inform each stage of clinical decision-making and service delivery. This requires that psychologists apply their knowledge of the best available research in the context of specific client characteristics, cultural backgrounds, and treatment preferences.

Consistent with ethical codes and professional standards, evidence-based practice entails the monitoring and evaluation of services provided to clients throughout treatment (from initial intake to treatment termination and maintenance of gains). Evidence-based psychological practice also pertains to one's own professional development. This requires a commitment to continually inform and/or be informed by research evidence so as to identify and select interventions and treatment strategies that maximize the chance of benefit, minimize the risk of harm, and deliver the most cost-effective treatment. 
Evidence-based practice relies, first and foremost, on research findings published in the peer-reviewed scientific literature including, at a minimum, treatment process and treatment outcome research. All research methodologies have the potential to provide relevant evidence, but in examining the scientific literature preference should always be given to studies based on research methodologies that, as much as possible, control threats to the validity of the research findings. Consistent with their academic training, psychologists are expected to thoughtfully evaluate the peer-reviewed scientific literature, recognizing both the applied value and the limitations of current knowledge. A number of avenues are available for psychologists to maintain their knowledge of the relevant scientific literature, including reliance on primary studies, systematic reviews, and clinical practice guidelines.

Respect for the dignity of persons is imperative in evidence-based practice. Psychologists work in collaboration with their clients in developing and implementing their services. Psychologists have knowledge of the research literature, which forms the basis for developing treatment options that may be indicated for a client with particular characteristics. Clients have valued lived experiences including previous symptoms or treatment experiences, preferences, and motivation. Communication and collaboration between the psychologist and the client is crucial to the process of achieving informed consent and reflects best practice based on current evidence.

\section{Sources and Levels of Evidence}

Evidence-based practice relies on diverse sources and levels of evidence. First and foremost, this evidence includes research findings published in the peer-reviewed scientific literature. For psychological practice, the evidence to be considered in recommending or providing a treatment should be derived from sources such as treatment outcome research, 
treatment process research, and basic psychological research that can be applied to clinical practice (see Figure 1). Following the initiation of treatment, data should be obtained from the ongoing monitoring of clients' reactions, symptoms, and functioning, and these data should inform decisions about treatment planning, modification, completion, and discontinuation.

To determine the strength and relevance of research findings to their practice, psychologists should consider the hierarchy of evidence available for the treatment options under consideration (see Figure 2). Although all research methodologies have some potential to provide relevant evidence, psychologists should first consider findings that are replicated across studies and that have utilized methodologies that address threats to the validity of obtained results (e.g., internal validity, external validity, generalizability, transferability). Thus, psychologists should consider the best available evidence highest on the hierarchy of research evidence. Evidence lower on the hierarchy should be considered only to the extent that better research evidence does not exist, or if there are clear factors that mitigate against using the best evidence (e.g., clear patient treatment preference).

Systematic knowledge syntheses are at the top of the hierarchy, as these are based on the results of multiple investigations. Systematic knowledge syntheses can include a range of methodologies, including systematic reviews, meta-analyses, meta-syntheses, realist syntheses, narrative syntheses, and practice guidelines that systematically synthesize evidence. When systematic knowledge syntheses are not available, psychologists should refer to primary research studies based on methodologies that address threats to the value of the research findings. For example, in quantitative research, randomized controlled trials can provide evidence with strong internal validity; in treatment research, these studies are typically known as efficacy studies. However, it is also important for psychologists to consider the external validity of research 
findings, and to consider the results of studies designed to have high external validity (i.e., generalizability); in treatment research, these studies are often referred to as effectiveness studies. Ideally, psychologists should consider studies that have high internal validity and studies that have high external validity.

There is likely to be process and outcome research relevant for many of the treatments provided by psychologists, and psychologists are expected to keep current with respect to new developments in the field. In those cases where there may be little or no relevant treatment research, practice guidelines may be available that are based on a consensus among experts and have been determined by formalized methods. Additionally, other options may be considered, although none of them are truly evidence-based. Such options are at the lowest level of the evidence hierarchy, and include unpublished practice-based data, prior clinical experience, and professional opinions not based on published research.

Regardless of the nature or strength of the evidence used to inform treatment selection and planning, psychologists should be prepared to alter the treatment being provided based on data from ongoing treatment monitoring (including both in-session and between-session client reactions and changes in symptoms and functioning). Frequently this will involve adjusting the content, sequencing, timing, or pacing of treatment elements. In some instances, this might lead to a decision, made in collaboration with the client, to discontinue the treatment and make a referral to another treatment provider. In such situations, psychologists should reconsider the relevant hierarchy of evidence in order to determine alternative options that might be appropriate for the client.

\section{Vignette Examples}


The Task Force believed that the relevance and usability of the report would be enhanced considerably by the inclusion of clinical vignettes that illustrate the use of the hierarchy in actual clinical practice. Vignettes are commonly utilized in clinical and academic materials; they are effective teaching tools because they provide relevant, accessible and interesting examples to consider and reflect upon (Pettifor, McCarron, Schoepp, Stark, \& Stewart, 2010).

Task Force members, Chairs of relevant CPA Sections and other psychologists were invited to submit brief vignettes of composite cases describing various aspects of the use of evidence-based treatment and the application of the hierarchy. The primary objective of the brief vignettes was to illustrate the process of evidence-based decision-making and practice. Our intention was not to be exhaustive, but rather to provide several short examples that reflect actual clinical decision-making and the process of applying EBP in psychological treatment.

We also solicited more extended vignettes from various experts in the field. As noted earlier, clinicians are expected to practice in an evidence-based manner and have an ethical and professional responsibility to provide the best treatment for a particular client based on the research evidence available. As such, clinicians should utilize the hierarchy of research evidence to determine which approach to treatment is optimal (and to revisit this hierarchy when necessary). These extended vignettes were intended to demonstrate evidence-based thinking once the initial treatment decision-making process had taken place. Their purpose was to illustrate the process of being evidence-based in one's assessment, conceptualization, therapeutic planning and treatment implementation.

A variety of therapeutic approaches are efficacious for unipolar depression and dysthymia (Australian Psychological Society, 2010; Beck \& Dozois, 2011; Goldman, Greenberg, \& Angus, 2006; Hollon, Thase, \& Markowitz, 2002; Hunsley, Elliott, \& Therrien, 2013; 
Leichsenring \& Leibing, 2007). Utilizing the same basic case example of depression, three extended vignettes focused on evidence-based assessment, case formulation, treatment planning, and implementation from cognitive therapy, emotion-focused therapy and brief psychodynamic psychotherapy approaches. A separate case was used to illustrate evidence-based reasoning from an interpersonal psychotherapy perspective. Research findings published in the peer-reviewed scientific literature including treatment outcome research, therapy process research, and basic research that can be applied to clinical practice were highlighted to demonstrate the process of evidence-based practice and the thoughtful evaluation of the peer-reviewed scientific literature (see www.cpa.ca/aboutcpa/committees/cpataskforces). The inclusion of different treatment protocols in response to the same basic clinical presentation was meant to underscore the reality that in some instances, the literature supports the efficacy of several treatment approaches. In such cases what is important is that clinicians' decisions are guided by the best available evidence combined with their existing skill base and consideration of the treatment approach that best matches a given client's preferences and/or disposition.

\section{Recommendations to the CPA Board of Directors}

The final component of the Task Force report involved a series of specific recommendations for the CPA Board of Directors to help ensure that this document exhibited clinical utility and demonstrated longevity. The Task Force members discussed the implications and scope of the report and made specific recommendations to the CPA Board relating to ethical principles, accreditation standards, dissemination and continuing education. These recommendations are reviewed briefly below.

\section{Canadian Code of Ethics}


The Values Statement accompanying Principle I of the Canadian Code of Ethics (Respect for the Dignity of Persons) states "Rights to privacy, self-determination, personal liberty, and natural justice are of particular importance to psychologists, and they have a responsibility to protect and promote these rights in all of their activities. As such, psychologists have a responsibility to develop and follow procedures for informed consent, confidentiality, fair treatment, and due process that are consistent with those rights" (Canadian Psychological Association, 2000, p.8). Contained within Value I are several standards addressing the issue of informed consent.

The EBP Task Force recommended that Standard I.17 be expanded to read: "I.17 Recognize that informed consent is the result of a process of reaching an agreement to work collaboratively, rather than of simply having a consent form signed. This includes ensuring those receiving services from psychologists are apprised of available evidence-based treatment options and the psychologists' ability to provide those services effectively and efficiently" (Canadian Psychological Association, 2000, p. 9).

The Values Statement accompanying Principle II of the Canadian Code of Ethics (i.e., Responsible Caring) states "A basic ethical expectation of any discipline is that its activities will benefit members of society....Therefore, psychologists demonstrate an active concern for the welfare of any individual, family, group, or community with whom they relate in their role as psychologists" (Canadian Psychological Association, 2000, p. 15). The statement underscores the importance of developing and using methods that will maximize benefit while minimizing potential harm to recipients of psychological services. Implied in this statement is the centrality of relying on empirical evidence to guide case formulation, treatment planning, and clinical intervention. 
The EBP Task Force concluded that this section of the Canadian Code of Ethics would be strengthened by the addition of a direct statement recommending that ethical psychological practice is guided by empirical evidence and use of the evidence hierarchy. Suggested wording could be:

II.21 Strive to provide and/or obtain the best possible service for those needing and seeking psychological service. This may include, but is not limited to, selecting interventions that are relevant to the needs and characteristics of the client that are evidence-based and guided by the evidence hierarchy, and that have reasonable theoretical or empirically-supported efficacy in light of those needs and characteristics (Canadian Psychological Association, 2000, pp. 16-17).

\section{Accreditation Standards}

The Accreditation Standards for Doctoral and Internship Programs in Professional Psychology (Canadian Psychological Association, 2011) stipulate that "Training in the practice of psychology includes a range of assessment and intervention procedures and is not restricted to a single type. Although programmes may emphasize different theoretical models and skills, students need to become familiar with the diversity of major assessment and intervention techniques in common use and their theoretical bases. Programmes must include training in evidence-based interventions as well as training in more than one therapeutic modality" (p. 21). This standard serves as an essential foundation for EBP for developing professional psychologists. The EBP Task Force recommended that the accreditation panel consider expanding this standard to include instruction and training in evidence-based decision-making that is guided by use of the evidence hierarchy.

\section{Dissemination of Evidence-Based Practice Methods}


The EBP Task Force recommended that the Education Directorate, Practice Directorate, and Science Directorate of CPA take steps to disseminate the findings and conclusions of the EBP Task Force and look for opportunities to sponsor or provide continuing education workshops, seminars, and symposia to psychologists in EBP and EBP decision making. The annual convention of the Canadian Psychological Association and annual meetings of Provincial and Territorial Psychological Associations and Societies can serve as vehicles for these sessions. In June 2013, for example, a workshop was presented that highlighted the Task Force's recommendations, outlined the application of the hierarchy to everyday practice and reviewed some online search strategies (Dozois, Mikail, Hunsley, \& Bieling, 2013; cf. Falzon, Davidson, \& Bruns, 2010). Unfortunately, most psychologists are familiar with only a couple of search tools (typically PsycINFO® and Medline®). Berke, Rozell, Hogan, Norcross, and Karpiak (2011), for instance, surveyed 549 psychologists about their knowledge of various online resources. Although most respondents were familiar with PsycINFO ${ }^{\circ}$ and Medline ${ }^{(67 \%}$ and $62 \%$, respectively), other databases were less well known (e.g., only $25 \%$ knew about the Cochrane Database of Systematic Reviews and merely $18 \%$ were familiar with the National Institute for Health Care Excellence). These findings underscore the importance of working toward providing opportunities for training in search strategies relevant to the EBP hierarchy.

Dissemination to the general public and other professional audiences should also be considered. The Task Force recommended that the "Getting the Best Psychological Help" Guide (embedded in the Task Force report) be distributed widely for display in offices of other health care providers (e.g., General Practitioners and Specialists, Chiropractors, hospital waiting areas, and various consumer-based groups such as the Canadian Cancer Association). The Task Force also recommended that this guide for individuals with lived experience be posted on the CPA 
Psychology Works web page. Developing different iterations of this guide to target specific segments of the community (youth, various ethnic and cultural groups) would also be a valuable service to the public. The guide that is presented in the Task Force report is intended to help individuals to seek out treatment that is based on the best available research and clinical evidence

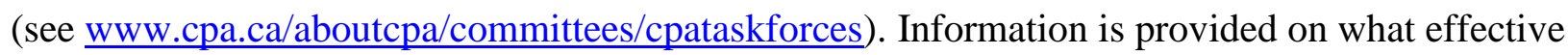
psychological treatment entails, why evidence-based practice is important, how to determine if a psychologist practices in an evidence-based manner and why the monitoring of treatment outcome is important.

\section{Graduate Training and Continuing Education}

Standard II.9 of the Canadian Code of Ethics states that psychologists "[k]eep themselves up to date with a broad range of relevant knowledge, research methods, and techniques, and their impact on persons and society, through the reading of relevant literature, peer consultation, and continuing education activities, in order that their services or research activities and conclusions will benefit and not harm others" (Canadian Psychological Association, 2000, p. 16).

The EBP Task Force recommended that the CPA Sections offering or sponsoring CE activities at the annual convention, or as stand-alone workshops, ensure that these offerings reflect EBP and EBP decision-making. Although not explicitly recommended in the Task Force report, we hope that graduate programs in clinical psychology will also use this document to engage students in discussion of evidence-based practice. Although students will benefit from training in specific empirically supported treatments, limiting the curriculum to this alone is insufficient. We also need to train psychologists in evidence-based practice (Babione, 2010; Bauer, 2007; Hershenberg, Drabick \& Vivian, 2012; Hunsley, 2007b; Lee, 2007; Leffler, Jackson, West, McCarty \& Atkins, 2013). Students need to learn how to think critically, respect 
and understand scientific knowledge and empirical methodologies, and integrate this information to make scientifically-informed clinical decisions within the context of a patient's needs and background. In this way, our students will be better positioned to think in an evidence-based manner and fully integrate new research into their practices.

\section{Conclusion}

The overriding objective of the CPA Task Force on Evidence-Based Practice of Psychological Treatments was to produce a report and a set of recommendations that would respond to the needs of both professional psychologists and individuals who are in need of psychological treatment. Below we list, in bulleted form, the executive summary of the Task Force report. We hope that readers will take time to go through the full Task Force report and consider the spirit of the evidence-based practice, the necessity of rigorous scientific data and the importance of keeping up-to-date.

\section{Summary Points}

- Evidence for recommending or providing treatment should stem from treatment outcome research, treatment process research, and basic psychological research.

- Before providing treatment, psychologists should first consider the hierarchy of evidence available for the treatment options under consideration.

- Psychologists should utilize the best available evidence (evidence which is highest on the hierarchy) which includes findings that are replicated across studies and that have used methodologies that address threats to validity (e.g., randomized controlled trials to address threats to internal validity, naturalistic studies to address threats to external validity). 
- In cases where there may be little or no relevant treatment research, practice guidelines may be available that are based on a consensus among experts and have been determined by formalized methods.

- Psychologists should frequently and systematically monitor clients' reactions, symptoms and functioning during treatment.

- Psychologists should be prepared to alter the treatment based on data from ongoing treatment monitoring, discussions with the client, and reconsideration of the relevant hierarchy of evidence. 


\begin{abstract}
Authors' Note
We would like to thank everyone who contributed by providing feedback on earlier drafts of the Task Force report. In particular, we would like to thank individual CPA members who responded to our initial request for consultation, various partner organizations (e.g., ACPRO, CCPPP, CRHSPP), Chairs of CPA Sections and members of the CPA Board of Directors. A number of individuals also worked hard to contribute clinically-relevant, interesting and thought-provoking vignettes that illustrate the process of being evidence-based in one's practice. We would like to acknowledge their hard work and thank them for their important contributions. Contributors to the Brief Vignettes: Dr. Lynn Alden, Dr. Peter Bieling, Dr. Guy Bourgon, Dr. David Dozois, Dr. Karen Dyck, Dr. David Hodgins, Dr. John Hunsley, Dr. Charlotte Johnston, Dr. Debra Lean, Dr. Sam Mikail, Dr. Jennifer Mills, Ms. Rachel Vella-Zarb and Dr. Margo Watt. Contributors to the Extended Vignettes: Dr. David A. Clark, Dr. Leslie Greenberg, Dr. Diana Koszycki, Dr. Michelle Presniak, Dr. Giorgio Tasca and Dr. Serine Warwar.
\end{abstract}




\section{References}

APA Presidential Task Force on Evidence-Based Practice. (2006). Evidence-based practice in psychology. American Psychologist, 61, 271-285.

Australian Psychological Society (2010). Evidence-based Psychological Interventions: A Literature Review (Third Edition). Melbourne, VIC: Author.

Babione, J. M. (2010). Evidence-based practice in psychology: An ethical framework for graduate education, clinical training, and maintaining professional competence. Ethics \& Behavior, 20, 443-453.

Baker, T. B., McFall, R. M., \& Shoham, V. (2008). Current status and future prospects of clinical psychology: Toward a scientifically principled approach to mental and behavioral health care. Psychological Science in the Public Interest, 9, 67-103.

Bauer, R. M. (2007). Evidence-based practice in psychology: Implications for research and research training. Journal of Clinical Psychology, 63, 685-694.

Beck, A. T., \& Dozois, D. J. A. (2011). Cognitive therapy: Current status and future directions. Annual Review of Medicine, 62, 397-409.

Berke, D. M., Rozell, C. A., Hogan, T. P., Norcross, J. C., \& Karpiak, C. P. (2011). What clinical psychologists know about evidence-based practice: Familiarity with online resources and research methods. Journal of Clinical Psychology, 67, 329-339.

Bohart, A. C. (2005). Evidence-based psychotherapy means evidence-informed, not evidencedriven. Journal of Contemporary Psychotherapy, 35, 39-53.

Bryceland, C., \& Stam, H. (2005). Empirical validation and professional codes of ethics: Description or prescription? Journal of Constructivist Psychology, 18, 131-155. 
Canadian Psychological Association (2011). Accreditation standards and procedures for doctoral programmes and internships in professional psychology ( $5^{\text {th }}$ ed.). Ottawa, ON: Author.

Canadian Psychological Association (2000). Canadian Code of Ethics for Psychologists ( ${ }^{\text {rd }}$ Ed.). Ottawa: ON: Author.

Chambless, D.L., \& Ollendick, T.H. (2001). Empirically supported psychological interventions: controversies and evidence. Annual Review of Psychology, 52, 685-716.

Chambless, D.L., Sanderson, W.C., Shoham, V., Bennett Johnson, S., Pope, K.S., CritsChristoph, P., Baker, M., Johnson, B., Woody, S.R., Sue, S., Beutler, L., Williams, D.A., \& McCurry, S. (1996). An update on empirically validated therapies. The Clinical Psychologist, 49, 5-18.

Dozois, D. J. A. (2013). Presidential address - Psychological treatments: Putting evidence into practice and practice into evidence. Canadian Psychology, 54, 1-11.

Dozois, D. J. A. (2012). From the president's desk - CPA Task Force on Evidence-Based Practice of Psychological Treatments: An update and request. Psynopsis, 34 (2), 7-10.

Dozois, D. J. A., Mikail, S., Hunsley, J., \& Bieling, P. J. (2013, June). Evidence-based practice of psychological treatments: Task force recommendations, online search strategies and application of the hierarchy. Workshop presented at the annual meeting of the Canadian Psychological Association, Quebec City, Quebec.

Duncan, B. L., \& Reese, R. J. (2012). Empirically supported treatments, evidence-based treatments, and evidence-based practice. Handbook of psychology $\left(2^{\text {nd }}\right.$. ed). New York: Wiley. 
Falzon, L., Davidson, K. W., \& Bruns, D. (2010). Evidence searching for evidence-based psychology practice. Professional Psychology: Research and Practice, 41, 550-557.

Goldman, R., Greenberg, L. \& Angus, L. (2006). The effects of adding emotion-focused interventions to the therapeutic relationship in the treatment of depression. Psychotherapy Research, 16, 537-549.

Hershenberg, R., Drabick, D. A. G., Vivian, D. (2012). An opportunity to bridge the gap between clinical research and clinical practice: Implications for clinical training. Psychotherapy, 49, 123-134.

Hollon, S. D., Thase, M. E., \& Markowitz, J. C. (2002). Treatment and prevention of depression. Psychological Science in the Public Interest, 3, 39-77.

Hunsley, J. (2007a). Addressing key challenges in evidence-based practice in psychology. Professional Psychology: Research and Practice, 38, 113-121.

Hunsley, J. (2007b). Training psychologists for evidence-based practice. Canadian Psychology, $48,32-42$.

Hunsley, J., Dobson, K. S., Johnston, C., \& Mikail, S. F. (1999a). Empirically supported treatments in psychology: Implications for Canadian professional psychology. Canadian Psychology, 40, 289-302.

Hunsley, J., Dobson, K. S., Johnston, C., \& Mikail, S. F. (1999b). The science and practice of empirically supported treatments. Canadian Psychology, 40, 316-319.

Hunsley, J., Elliott, K., \& Therrien, Z. (2013). The efficacy and effectiveness of psychological treatments. Ottawa: Canadian Psychological Association. 
Hunsley, J., \& Lee, C. M. (2007). Research-informed benchmarks for psychological treatments: Effiacy studies, effectiveness studies, and beyond. Professional Psychology: Research and Practice, 38, 21-33.

Kazdin, A. E. (2008). Evidence-based treatment and practice: New opportunities to bridge clinical research and practice, enhance the knowledge base, and improve patient care. American Psychologist, 63, 146-159.

Lee, C. M. (2007) From clinical trials to professional training: A graduate course in evidencebased interventions for children, youth, and families. Training and Education in Professional Psychology, 1, 215-223.

Lee, C. M., Horvath, C., \& Hunsley, J. (2013). Does it work in the real world? The effectiveness of treatments for psychological problems in children and adolescent. Professional Psychology: Research and Practice, 44, 81-88.

Leffler, J. M., Jackson, Y., West, A. E., McCarty, C. A., \& Aitkins, M. S. (2013). Training in evidence-based practice across the professional continuum. Professional Psychology: Research and Practice, 44, 20-28.

Leichsenring, F., \& Leibing, E. (2007). Psychodynamic psychotherapy: A systematic review of techniques, indications and empirical evidence. Psychology and Psychotherapy: Theory, Research and Practice, 80, 217-228.

Lilienfeld, S. O. (2010). Can psychology become a science? Personality and Individual Differences, 49, 281-288.

Lilienfeld, S. O., Ritschel, L. A., Lynn, S. J., Cautin, R. L., \& Latzman, R. D. (in press). Why many clinical psychologists are resistant to evidence-based practice: Root causes and constructive remedies. Clinical Psychology Review. 
Pettifor, J. L., McCarron, M. C. E., Schoepp, G., Stark, C., \& Stewart, D. (2010). Resource guide for psychologists: Ethical supervision in teaching, research, practice and administration. Ottawa, Ontario: Canadian Psychological Association.

Spring, B. (2008). Evidence-based practice in clinical psychology: What it is, why it matters; what you need to know. Journal of Clinical Psychology, 63, 611-631.

Stuart, R. B., \& Lilienfeld, S. O. (2007). The evidence missing from evidence-based practice. American Psychologist, 62, 615-616.

Treat, T. A., Bootzin, R. R., \& Baker, T. B. (Eds.). (2012). Psychological clinical science: Papers in honor of Richard M. McFall. Routledge.

Westen, D., \& Morrison, K. (2001). A multidimensional meta-analysis of treatments for depression, panic, and generalized anxiety disorder: An empirical examination of the status of empirically supported therapies. Journal of Consulting and Clinical Psychology, 69, 875-899. 


\section{Figure Captions}

Figure 1. Sources of evidence that inform clinical practice.

Figure 2. The hierarchy of research evidence related to clinical practice. 
Evidence-Based Practice 27

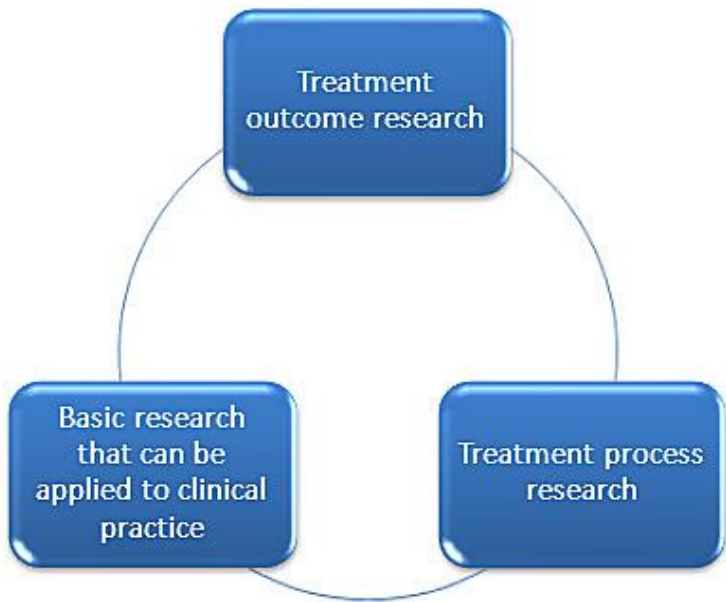



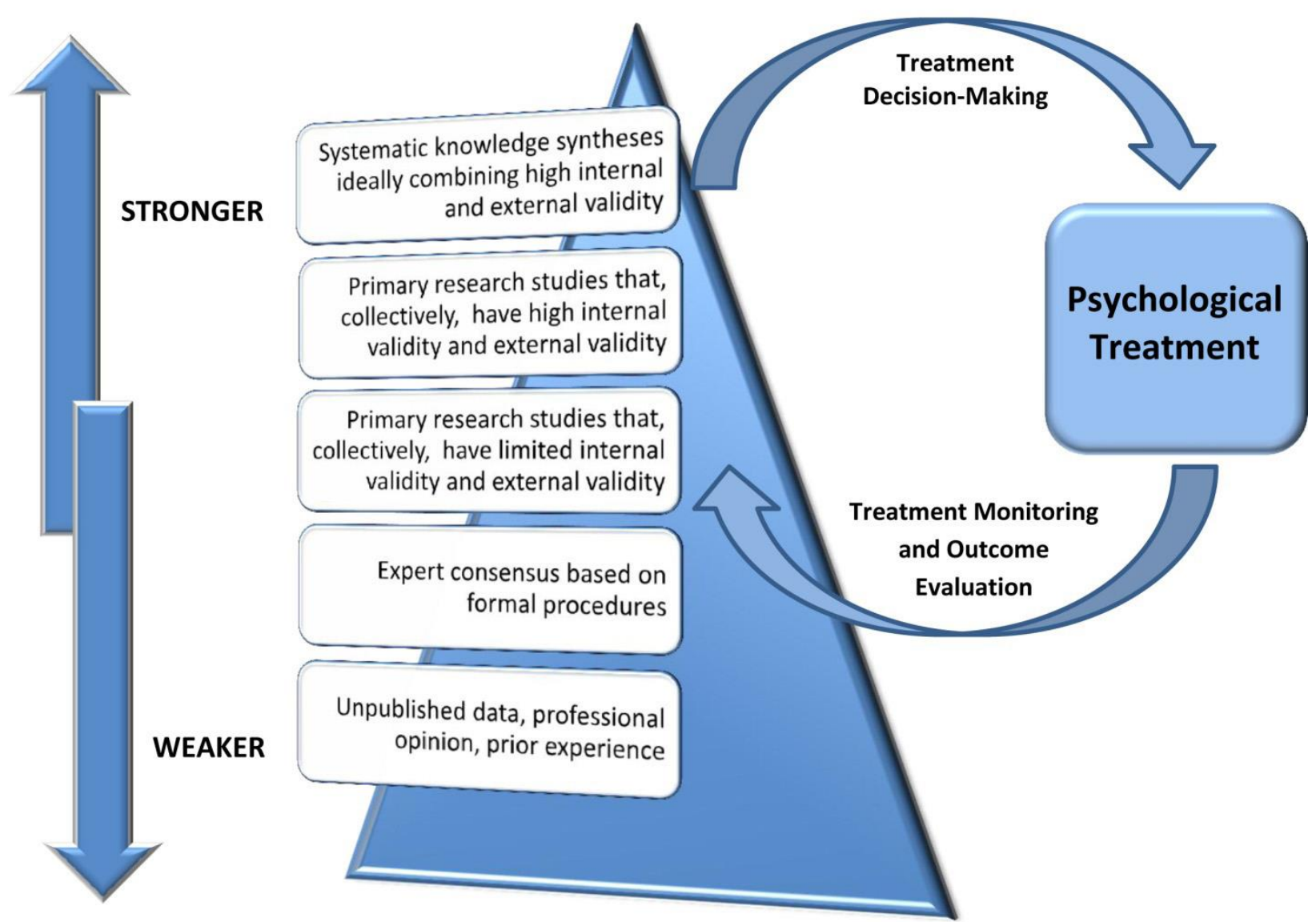